\title{
Subphonemic and Suballophonic Consonant Variation: The Role of the Phoneme Inventory
}

\author{
Lisa M. Lavoie \\ Research Laboratory of Electronics, Speech Communication Group \\ Massachusetts Institute of Technology \\ lisa@speech.mit.edu
}

\begin{abstract}
Consonants exhibit more variation in their phonetic realization than is typically acknowledged, but that variation is linguistically constrained. Acoustic analysis of both read and spontaneous speech reveals that consonants are not necessarily realized with the manner of articulation they would have in careful citation form. Although the variation is wider than one would imagine, it is limited by the phoneme inventory. The phoneme inventory of the language restricts the range of variation to protect the system of phonemic contrast. That is, consonants may stray phonetically into unfilled areas of the language's sound space. Listeners are seldom consciously aware of the consonant variation, and perceive the consonants phonemically as in their citation forms. A better understanding of surface phonetic consonant variation can help make predictions in theoretical domains and advances in applied domains.
\end{abstract}

\section{Consonant variation}

The consonant variation of interest here goes beyond well-recognized allophonic variation. This variation is not necessarily conditioned by position in word, position in syllable or by segmental context as allophonic variation is, but rather by other factors. In several areas, work has been done on variation that can be considered suballophonic, as opposed to strictly allophonic. Consonants have been found to respond phonetically to a range of conditioning environments, with: hyperarticulation under stress (De Jong 1995), reinforcement in prominent prosodic positions (Fougeron 1998, Fougeron \& Keating 1997), reduction in colloquial speech (e.g., Brown 1990, Kohler 1990), and reduction in highly predictable words (Jurafsky et al. 1998). Even if these kinds of phonetic differences are noticed, they are seldom considered part of a language's phonology proper. Many factors, above and beyond those just mentioned, impinge upon a consonant's realization. This paper presents data that illustrate the role of the language's phoneme inventory in constraining some of that variation.

\section{$1.1 \quad$ Instrumental work}

Because so much consonant variation escapes the ear, instrumental work is essential to gathering accurate data. Lavoie (2001) located much more variation in consonants than was expected based on the available literature. Lexical knowledge and categorical perception both make it difficult to hear all of the variation that is present in consonants. Barry (1996, p. 115) explains the need to examine spectrograms, in addition to listening and transcribing the speech.

[...], the visual scrutiny of graphically presented instrumental analyses, particularly the use of good spectrograms as an accompaniment to careful auditory examination can serve to augment (and correct) the auditory analysis of even the most expert transcriber. 
One case where spectrograms are nearly essential is the case of unreleased stops. With a spectrogram, the presence or absence of a release burst is easily verified. Bursts are not always detectable when listening to continuous speech. Missing the burstless stops is likely due to the ways in which linguists are trained to identify phonetic segments and assign them symbols, which focuses on elements which are phonemic in some language. Since burstless stops are never phonemic in any language, there are no unitary symbols for them and linguists have less training in discerning them from other segments. Hearing unreleased stops in continuous speech, perhaps intervocalically, is quite hard. Other kinds of variation, especially variation in consonant manner, is also quite hard to hear. The next section consists of a more detailed discussion of $/ \mathrm{k} /$ to set the stage for examining its variation in spontaneous American English speech.

\subsection{American English / $\mathrm{k} /$}

American English / $/$ / displays more variation than is typically reported. As a velar stop, /k/ should be articulated with a full closure, formed by raising the tongue dorsum to the velum (soft palate). The midsagittal section of the vocal tract below in (1) illustrates the position of the articulators for a canonical stop $/ \mathrm{k} /$ and the spectrogram in (2) illustrates the pattern resulting from articulation of a canonical $/ \mathrm{k} /$. The $/ \mathrm{k} /$ consists of a silent closure, release burst and brief period of aspiration.

(1) Midsagittal section of /k/ articulation (Language Files 1999)

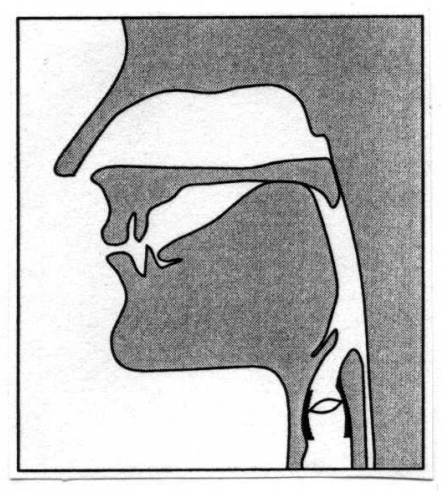

(2) Spectrogram of canonical /k/ in the word jackass closure $\downarrow \downarrow$ release burst

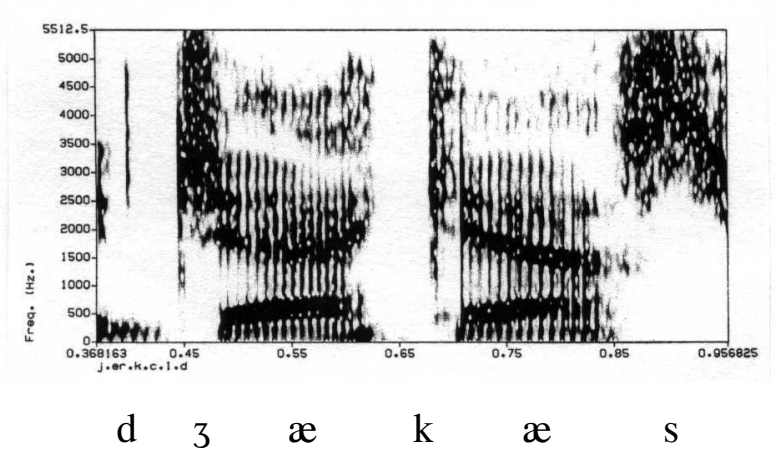

Although $/ \mathrm{k} /$ is supposed to be a complete stop, it is frequently realized with other manners of articulation, especially in spontaneous speech. This is variation above and beyond the 
commonly-noted /k/ variation of aspiration or fronting. According to Ohala (1996:206): "The more we look at connected speech in detail, the larger the 'zoo' of strange and exotic phonetic animals becomes." Ohala is certainly correct in that some of the most interesting, and perhaps even shocking, realizations of $/ \mathrm{k} /$ are found in spontaneous speech, where $/ \mathrm{k} /$ is not necessarily a complete stop. The two main ways in which $/ \mathrm{k} /$ could be less than a stop is for it to lose its closure and to lose its burst. An especially broad range of realizations of $/ \mathrm{k} /$ comes from MIT's American English Map Task recordings.

\subsection{MIT American English Map Task}

The MIT Map Task recordings, based on the Human Communication Resource Centre (HCRC), or Edinburgh, Map Task (e.g. Anderson et al. 1993) were organized by Olga Goubanova, when she was a visitor at MIT in the Speech Communication Group of the Research Laboratory of Electronics in 1999. She recruited eight close female friends in their late teens and early twenties to participate. Seven of the speakers were from the northeastern United States and one was from California. The Map Task is done in pairs of speakers, with one direction giver and one direction follower. Each member of the pair is given a slightly different version of a map of the same fictional place. The direction giver's map has a route marked which she must convey to the direction follower, who will reproduce it on her map. Several complications make this task quite difficult. The maps do not show precisely the same set of landmarks and the landmarks sometimes have slightly different names (e.g. fast-running river vs. fast-flowing stream) on each map. The complications are intended to encourage dialogue between the speakers, and prevent a simple monologue from the direction giver. In the MIT recordings, the participants had no eye contact. The dialogues were recorded onto digital tape at a sampling rate of $16 \mathrm{kHz}$, with both dual channel and single channel versions eventually stored. Manipulations of the files were done using Waves+/ESPS signal analysis software. In the winter of 2001, I orthographically transcribed the sixteen Map Task conversations, which totaled two and a half hours of running speech.

In the MIT Map Task, /k/ shows a great deal of variation in its realization. Some of this range of variation is illustrated in the spectrograms in (3) through (6). In (3), / $\mathrm{k} /$ is an incompletely closed stop with some frication noise in it's like three inches; in (4), / $\mathrm{k} /$ is almost fully voiced in like diagonally; in $(5), / \mathrm{k} /$ is realized as an approximant, with full voicing and just an approximation of closure in like ; in $(6), / \mathrm{k} /$ is realized as a voiced non-velar fricative in kinda. In (3) through (5), the second and third formants of the preceding vowel come together, the velar pinch characteristic of a velar constriction, in the transition to the consonant. In (6), the formants show no evidence of a velar place of articulation; rather, the formants interpolate almost directly between the surrounding vowels, a pattern more characteristic of a glottal fricative.

(3) $/ \mathrm{k} /$ as incomplete stop with frication $\downarrow$

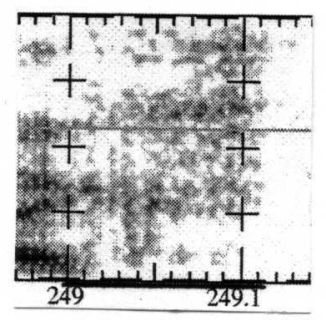

(4) $/ \mathrm{k} /$ with voicing $\downarrow$

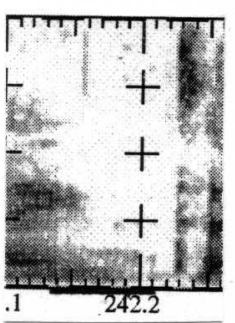

(5) $/ \mathrm{k} /$ as an approximant $\downarrow$

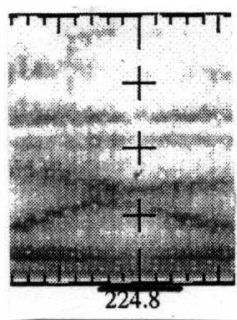

(6) $/ \mathrm{k} /$ as voiced glottal fricative $\downarrow$

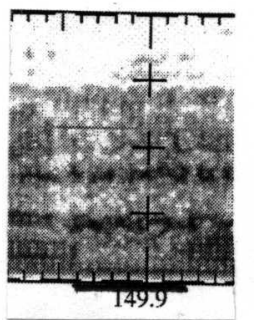


The spectrograms of $/ \mathrm{k} /$ from the Map Task show that $/ \mathrm{k} /$ can be realized with several kinds of differences from the canonical stop, either with an incomplete closure, as voiced, as an approximant, or as a non-velar fricative. All of these realizations are at odds with the fact that the only widely acknowledged allophones of $/ \mathrm{k} /$ are the fronted and unreleased versions, but have little to do with manner of articulation. While the conditioning environments for the precise manners of articulation of $/ \mathrm{k} /$ are not yet clear, it is clear is that the variables influencing the realizations are quite complex.

This work on $/ \mathrm{k} /$ is not the first to demonstrate variation from citation form. Other researchers have shown that consonants vary from their citation forms in numerous ways. These include differences in degree of constriction (e.g. Butcher 1996, Crystal \& House 1988, Engstrand \& Lacerda 1996, Helgason 1996), presence or absence of a burst (e.g. Duez 1995), aspiration, frication, affrication noise, spectral center of gravity (van Son \& Pols 1999), amount of formant structure visible, and vocal fold vibration. Although consonants can be produced with other than their canonical forms, they are not necessarily perceived any differently. Whalen, Best \& Irwin (1997) found that allophones of /p/ are stored as members of a single underlying category. Even in realizations that are not consistent with the citation forms, enough cues must remain to allow speakers access to the underlying segment.

\subsection{Acoustic study of variation in English and Spanish}

To study the variation in consonants from a controlled corpus, an acoustic study of variation in 20 American English and 17 Mexican Spanish consonants (Lavoie 2001) was carried out. This study reveals the extent of consonant variation even in relatively careful read laboratory speech. Consonants were all intervocalic in disyllabic words. The position in word (initial or medial) and the lexical stress (either onset to the syllable with primary lexical stress or not) were manipulated. Examples of words studied for $/ \mathrm{k} /$ in English and Spanish appear below, with the syllable bearing primary lexical stress underlined:

Initial Cocoa Cocaine

Medial maCaque jạCKass

\begin{tabular}{|c|c|}
\hline Words fo & lish /k/ \\
\hline Stressed & Unstressed \\
\hline Cocoa & Cocaine \\
\hline
\end{tabular}

$\begin{array}{ll}\text { Words for Spanish /k/ } \\ \text { Stressed } & \text { Unstressed } \\ \text { Cóco } & \text { coCól } \\ \text { coconut } & \text { bread roll } \\ \text { taCón } & \text { tạ } C o \\ \text { heel of shoe } & \text { heel, cue }\end{array}$

Five native English speakers and four native Spanish speakers read four repetitions at a time of the words embedded in a carrier phrase. With regard to reduction, the recording paradigm contains aspects that favor reduction and aspects that do not. The most important factor working against reduction is the fact that speakers read the words into a microphone in a soundproof recording booth in the Cornell Phonetics Laboratory. Factors favoring reduction are the fact that most of the speakers were friends of the experimenter, bringing a degree of ease to the recording task. Speakers were also quite relaxed and comfortable with the task because they had read the lists of words in carrier phrases several times already and the words were highly predictable, another conditioning factor for reduction (see, e.g. Bell et al. 1999).

The recordings were made on analog cassette and digitized onto Sun SparcStations for analysis with Waves+/ESPS software. Six repetitions of each word per speaker were analyzed. In this data, many consonants vary from their citation manner of articulation and degree of constriction. The variation is not categorical variation, but rather continuous or stochastic variation as Pierrehumbert (1994) describes. In fact, even the flapping of American 
English /t/ was not categorical in the data, as /t/ in the flapping environment, here medial and unstressed, was not consistently a flap.

\section{$1.5 \quad$ Results}

Some consonants in the data were very stable in the sense of being true to their manner of articulation in citation form. These were the voiceless sibilants in both English and Spanish, and the voiceless stops in Spanish. For other segments, though, over $10 \%$ of the tokens were realized with an unexpected manner of articulation. The manner is unexpected in the sense that it is not the citation or underlying manner of articulation. These segments are English $/ \mathrm{k}, \mathrm{d}, \mathrm{g}, \mathrm{d} 3, \theta, \mathrm{v}, \delta, \mathrm{z}, \mathrm{z} /$ and Spanish $/ \mathrm{t} \int \mathrm{f}, \mathrm{x}, \mathrm{r}, \beta, \delta, \mathrm{\gamma}, \mathrm{j} /$, summarized and given with example words below in (8). Recall that all segments were examined in four different words, such as shown in (7), not just the one word listed below.

(8) Consonants with more than $10 \%$ realized in another manner

$\begin{array}{cl} & \begin{array}{c}\text { English } \\ \text { example word }\end{array} \\ \mathrm{k} & \text { cocaine } \\ \mathrm{d} & \text { disease } \\ \mathrm{g} & \text { gazelle } \\ \mathrm{d} 3 & \text { July } \\ \theta & \text { Thoreau } \\ \mathrm{v} & \text { vignette } \\ \partial & \text { therein } \\ \mathrm{z} & \text { Zaire } \\ 3 & \text { Beijing }\end{array}$

\begin{tabular}{|c|c|}
\hline \\
\hline chocar & 'to strike' \\
\hline focal & 'focal' \\
\hline joyón & 'large jewel' \\
\hline miro & 'I look' \\
\hline borrar & 'to cross out \\
\hline dolar & 'to chop' \\
\hline gozar & 'to enjoy' \\
\hline llorón & 'mourner' \\
\hline
\end{tabular}

One might well ask, then, if so many segments are not realized in their appropriate citation form, what kind of variation do they exhibit?

Stops in the data are not always complete. They may be "stopless," that is, lack complete seals (e.g., Crystal \& House 1988, Shockey \& Gibbon 1993) or they may lack release bursts. Note that although numerous English voiceless stops were not complete stops and exhibited noise when there should have been silent closure, they are not true fricatives. Shockey \& Gibbon (1993) show that the oral airflow in incompletely closed stops is much less than the airflow for a true fricative. English voiced stops were often realized as approximants, lacking noise but appearing more like glides. The following spectrograms illustrate some of the variation in stops.

(9) English /k/ with incomplete seals and frication noise (first $/ \mathrm{k} /$ especially)

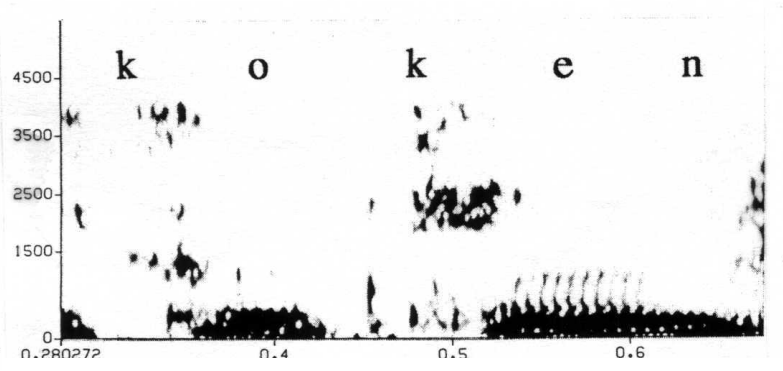

(10) English /g/ without release burst

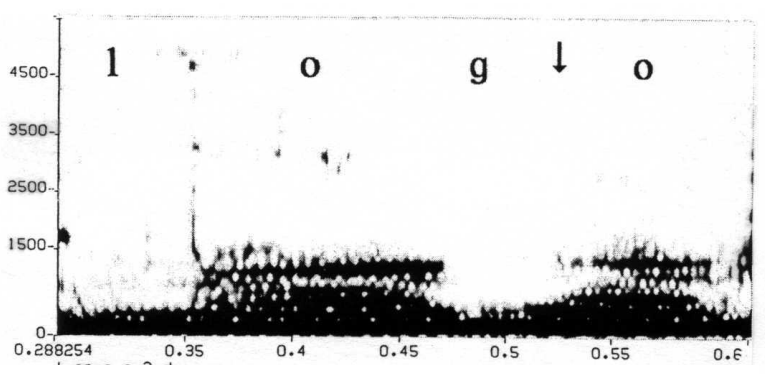


Phonemic fricatives are not always true noisy fricatives; they do not always have concentrated noise in the frequency range expected based on the place of articulation. Since the fricative manner falls between complete closure and approximation of closure, fricatives have two obvious directions in which to vary: they could become more closed or more open. English voiceless fricatives /f, $\theta$ / were sometimes produced with greater closure, as stops. Some English and Spanish fricatives were produced with less closure, as approximants or glides rather than noisy fricatives. In English, the non-sibilant voiced fricatives /v, $\partial /$ show the most variation in their manner of realization by varying in either direction, such that there were realizations as stops, true fricatives, approximants, or glides. Some of the variation in manner of articulation clusters in particular prosodic positions.

\subsection{Patterning in terms of sonority}

Some of the consonant variation can be explained with the phonological concept of sonority. Sonority highlights the tendencies seen in the data, but it is not entirely descriptive of the data, especially in the case of $/ \mathrm{k} /$ which shows variation regardless of the environment. With many segments of both English and Spanish, prosodic position tends to condition differences in sonority of the elements realized, in the following way:

- $\quad$ in unstressed or medial positions:

consonants may receive more sonorous realizations

- $\quad$ in stressed or initial positions:

consonants tend toward less sonorous realizations

Although sonority is a mature concept (e.g. Jespersen 1904), researchers still differ in the level of detail to include in a sonority hierarchy. The minimal sonority hierarchy shown below comes from Zec (1995). Her hierarchy focuses on the important distinction between obstruent, sonorant, and vowel.

(11) Sonority hierarchy (Zec 1995)
obstruent
least sonorous (least open vocal tract)
sonorant
vowel
most sonorous (most open vocal tract)

Using Zec's hierarchy, it is easy to illustrate how fricatives (a type of obstruent) may be realized, depending on their prosodic position. If the segment is a fricative in citation form, it may receive a less sonorous manifestation when it is word initial or stressed, so it could be a stop (least sonorous type of obstruent). If that same segment is word medial or unstressed, it may receive a more sonorous realization, so it could be an approximant or a glide (sonorant). While these generalizations are useful and descriptive of the results, they do not predict all of the possible consonant variation. Because sonority does not entirely explain all of the consonant variation, some of the other factors influencing the range of variation must be determined. The next section addresses the role of the phoneme inventory in limiting variation. 


\section{Role of the phonemic inventory in constraining variation}

No single factor explains all segmental variation, so it is important to examine numerous factors (see, e.g. Lavoie (to appear)). A variety of factors have already been shown or proposed to influence degree of reduction in words. For this paper, unless otherwise indicated, reduction refers roughly to a segment being realized with less oral closure than in its citation form.

Factors which influence more reduction in a word include:

- $\quad$ optional post-lexical phonology (Byrd 1994)

- predictability: words are shorter if they are more predictable (e.g. Bell et al. 1999)

- collocations: words in common collocations are more reduced (Jurafsky et al. 1998)

- previous use of the word in the discourse: words are shorter on their second utterance in a discourse (Fowler and Housum 1987)

- $\quad$ sex: male speakers reduce more than female speakers (Byrd 1994) and male speakers in TIMIT spoke 6.2\% faster than female (Byrd 1994, Jurafsky et al. 1998).

Factors which tend to ensure that words are less reduced, that is, realized very close to their citation forms, or perhaps even hyperarticulated, include:

- disfluency: words are reduced less around a disfluency (Fox, Tree and Clark 1997, Bell et al. 1999)

- first use of a word in a discourse: the first instance of a word in a discourse is less reduced (Fowler and Housum 1987)

- $\quad$ prominence: pitch-accented words are hyperarticulated (de Jong 1995)

- adjacency to higher-level prosodic boundaries: segments that are adjacent to prosodic boundaries of progressively larger size constituents show greater lengthening, indicating that they seldom reduce (e.g., Byrd 2000, Byrd et al. 2000, Byrd \& Saltzman 1998).

Some other factors induce differences in reduction, but it is not clear in precisely which direction. These include segmental context and prosodic position. Final consonants reduce less when the following word is vowel-initial (Bell et al. 1999). Glottal consonants /h, / $/$ are more vocalic in the vicinity of a pitch accent and more consonantal at phrase boundaries. Gestures have greater magnitude when they are in more prosodically prominent words (Pierrehumbert \& Talkin 1992).

The next section examines the role of the language's phoneme inventory, or set of contrastive segments, in constraining phonetic variation. These arguments are informed by earlier work suggesting that the phoneme inventory constrains coarticulation in vowels (Manuel 1990) and constrains variation in consonant place of articulation (Jongman, Blumstein \& Lahiri 1985). I will argue that variation in consonant manner of articulation is similarly constrained. 


\subsection{Vowels}

In her work on coarticulation in Bantu languages, Manuel (1990) compared several languages, and found that languages with more crowded vowel systems allow less anticipatory coarticulation than those with less crowded systems. To illustrate, consider an underlying form of $/ \mathrm{aCi} /$, with $\mathrm{C}$ being any consonant. In this case, anticipatory coarticulation between the vowels means that the low vowel /a/ is produced higher than normal, in anticipation of the coming high vowel /i/.

less crowded system $\rightarrow$ more raising of /a/ in anticipation of following high vowel more crowded system $\rightarrow$ less raising of / a/ in anticipation of following high vowel

These differences in amount of coarticulation are due to the need to keep contrastive phones separate. Manuel (1990:1286) states: "Languages will tend to tolerate less coarticulation just where extensive coarticulation would lead to confusion of contrastive phones." In (12) is an exaggerated diagram of the Ndebele and Sotho vowel spaces, derived from Manuel's results. The circles represent hypothetical extents of coarticulation of the vowel /a/. With only five contrasting vowels, and just one set of mid vowels, Ndebele tolerates raising of /a/. Although the vowel approaches the region of the vowel space occupied by /e, o/, it does not specifically enter the space. Sotho, with its lower mid vowels, on the other hand, cannot tolerate the same amount of $/ \mathrm{a} /$ raising. The same amount of coarticulation in Sotho would land / $\mathrm{a} /$ squarely in the space of the lower mid vowels, causing potential loss of contrast.
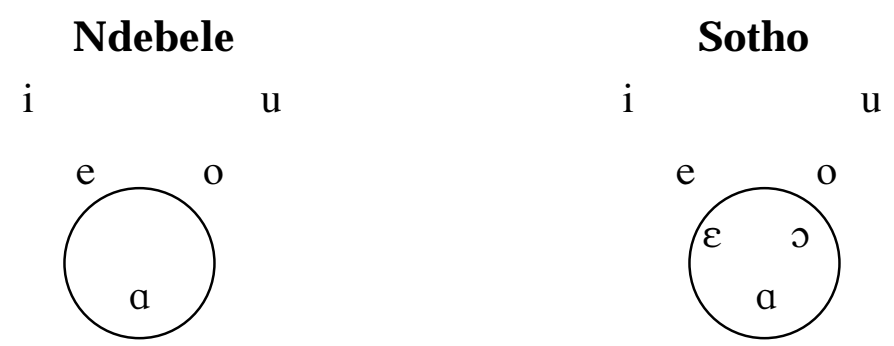

Manuel (1990:1296) summarizes her results:

[...] the vowel /a/ is more susceptible to anticipatory coarticulation with a following transconsonantal vowel in Shona $(L C)$ and Ndebele $(L C)$, which have no near phonemic neighbors to /a/, than in Sotho (MC), which does have relatively near neighboring and contrasting phonemic vowels. This result is consistent with the idea that coarticulation is limited by output constraints on phones, and that these output constraints are determined, in part, by the need to maintain phonological distinctions in a language.

\subsection{Consonant place of articulation}

Jongman, Blumstein \& Lahiri (1985) present the case of dental and alveolar stops in Malayalam, Dutch and English. They demonstrate that dental and alveolar stops in Malayalam can be accurately classified based on stop burst amplitude. They go on to study English alveolar and Dutch dental stops, finding these languages have more variation in stop place than Malayalam, based on stop burst amplitude. They attribute this fact to the three languages' different contrastive uses of the articulatory space for stops, as illustrated below. 
- Malayalam

- Dutch

- English
Contrasting Phonemes

dental and alveolar

dental only

alveolar only
Realization

distinct dental \& alveolar

dentals range over alveolars

alveolars range over dentals

English and Dutch display more variation in stop place categories than Malayalam does because English and Dutch do not need to distinguish between the dentals and alveolars. In the palate traces below (adapted from Ball \& Rahilly 1999:54), possible ranges of closure location are represented with dotted ovals for dentals and solid ovals for alveolars.

(13) Malayam (distinct dental and alveolar phonemes)

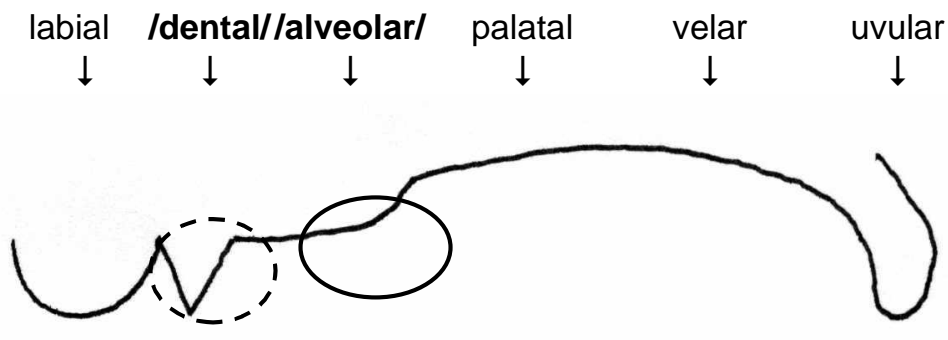

(14) Dutch (just the dental phoneme)

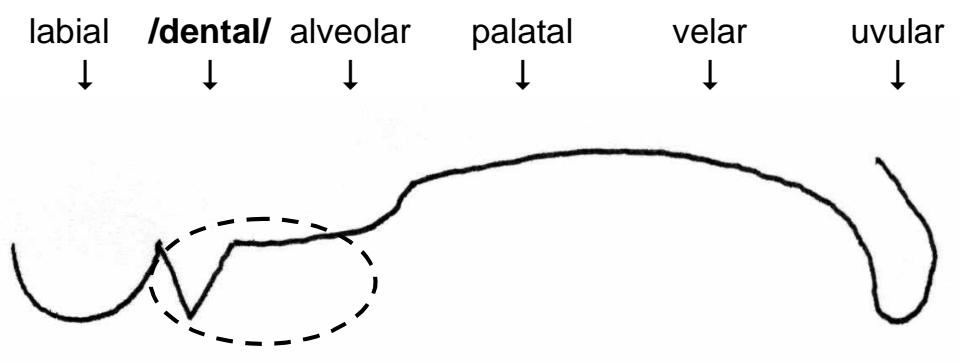

(15) English (just the alveolar phoneme)

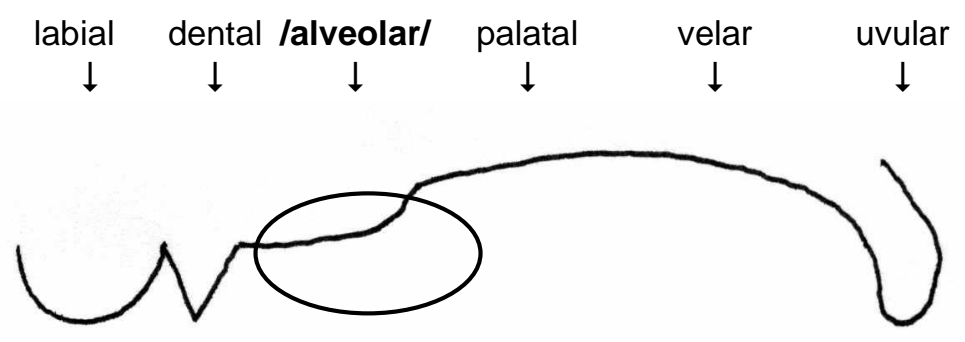

\subsection{Consonant manner of articulation}

Consonant variation has not received much attention with respect to manner. If consonant manner behaves as vowels and consonant place do, the inventory of contrastive elements should constrain manner variation. The voiceless velars in American English and Mexican Spanish provide a perfect test case for this prediction. Examples (16) and (17) below present inventories of voiceless stops and fricatives in Spanish and English. As is clear from the inventories, English has no contrastive voiceless velar fricative, but Spanish does. 
(16) Partial phoneme inventory of Spanish

\begin{tabular}{|l|c|c|c|}
\hline & labial & alveolar & velar \\
\hline stop & $\mathrm{p}$ & $\mathrm{t}$ & $\mathrm{k}$ \\
\hline fricative & $\mathrm{f}$ & $\mathrm{s}$ & $\mathrm{x}$ \\
\hline
\end{tabular}

(17) Partial phoneme inventory of English

\begin{tabular}{|c|c|c|c|}
\hline & labial & alveolar & velar \\
\hline stop & $\mathrm{p}$ & $\mathrm{t}$ & $\mathrm{k}$ \\
\hline fricative & $\mathrm{f}$ & $\mathrm{S}$ & \\
\hline
\end{tabular}

A canonical English / $\mathrm{k} /$ was illustrated earlier in (2) and a canonical Spanish / $\mathrm{k} /$ is illustrated in (18) below. Like the canonical English $/ \mathrm{k} /$, Spanish $/ \mathrm{k} /$ has a full closure and a release burst. There is no noise leaking through the closure in either of the two instances of $/ \mathrm{k} / \mathrm{in}$ (18). A canonical Spanish /x/, voiceless velar fricative, is illustrated in (19), with concentrations of frication noise at approximately 1500 and $4000 \mathrm{~Hz}$.

(18) Spanish /k/s in coca closure release closure release

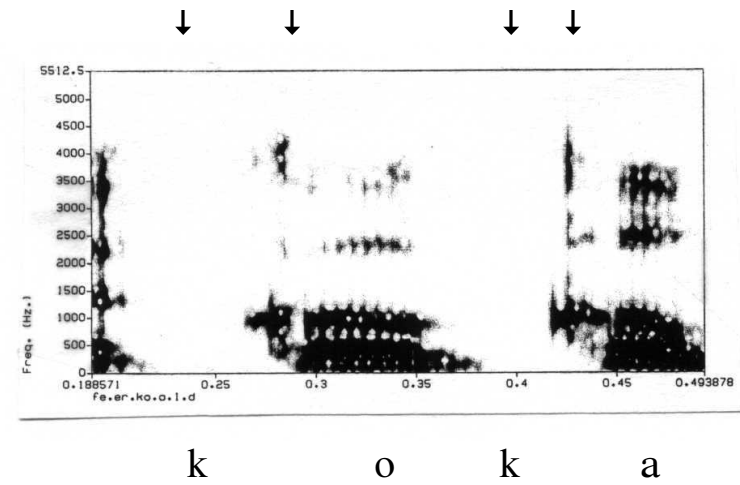

(19) Spanish /x/ in dejo

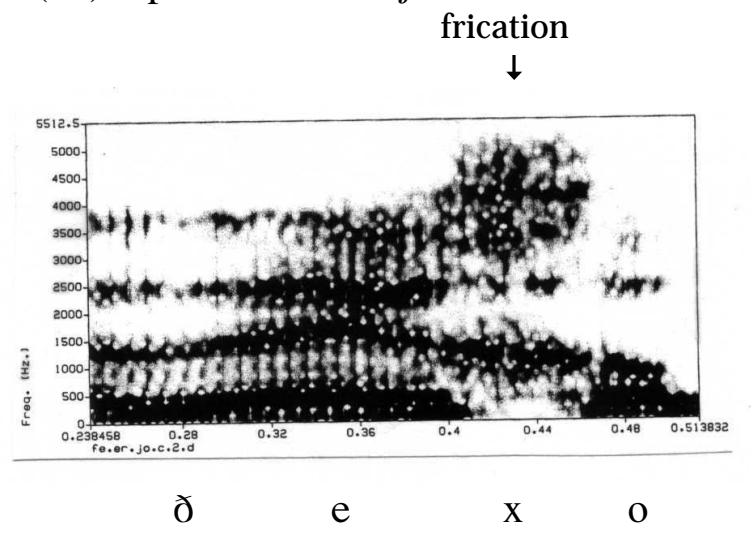

(20) and (21) present examples of English /k/ that differ from the canonical /k/. In (20), /k/ in cocaine has frication noise when it should have a silent closure, indicating that the segment is not realized as a complete stop. The realization of $/ \mathrm{k} /$ in (21) also shows frication noise, throughout the entire supposed closure. The $/ \mathrm{k} /$ realizations given are representative of the data. 
(20) English /k/ with frication noise in cocaine

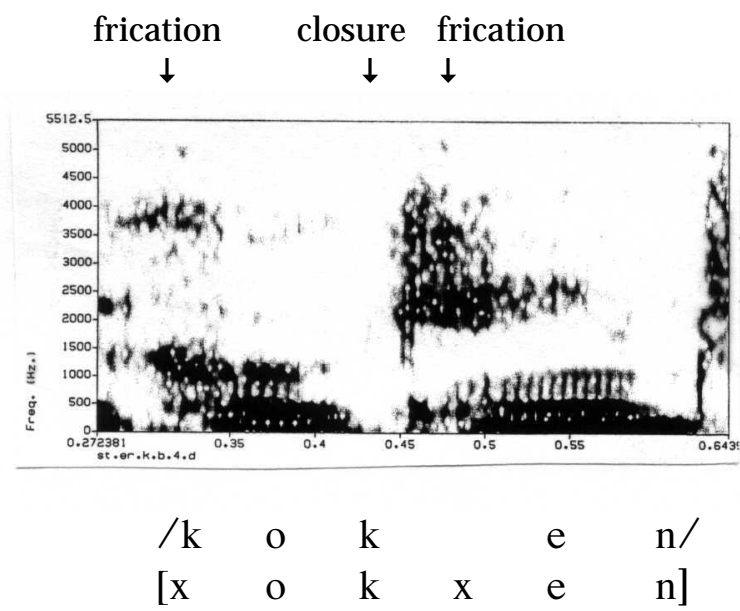

(21) English /k/ with frication in jackass

\section{frication}

$\downarrow$

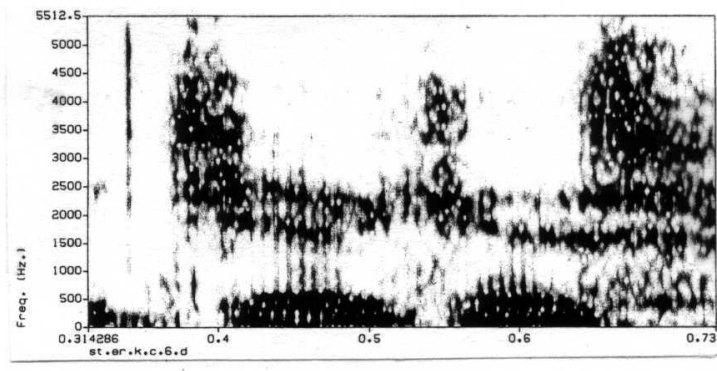

$\begin{array}{lllll}/ \mathrm{d} 3 & \mathfrak{x} & \mathrm{k} & \mathfrak{x} & \mathrm{s} / \\ {\left[\mathrm{d} \int\right.} & \mathfrak{x} & \mathrm{x} & \mathfrak{x} & \mathrm{s}]\end{array}$

The chart below summarizes all of the realizations of Spanish and English $/ \mathrm{k} /$ in the data that are not canonical stops. In Spanish $/ \mathrm{k} /$ is a stop $93 \%$ of the time, a fricative 3\% of the time and an approximant $4 \%$ of the time. In English, $/ \mathrm{k} /$ is a stop $79 \%$ of the time, some kind of fricative $13 \%$ of the time, and an approximant $8 \%$ of the time.

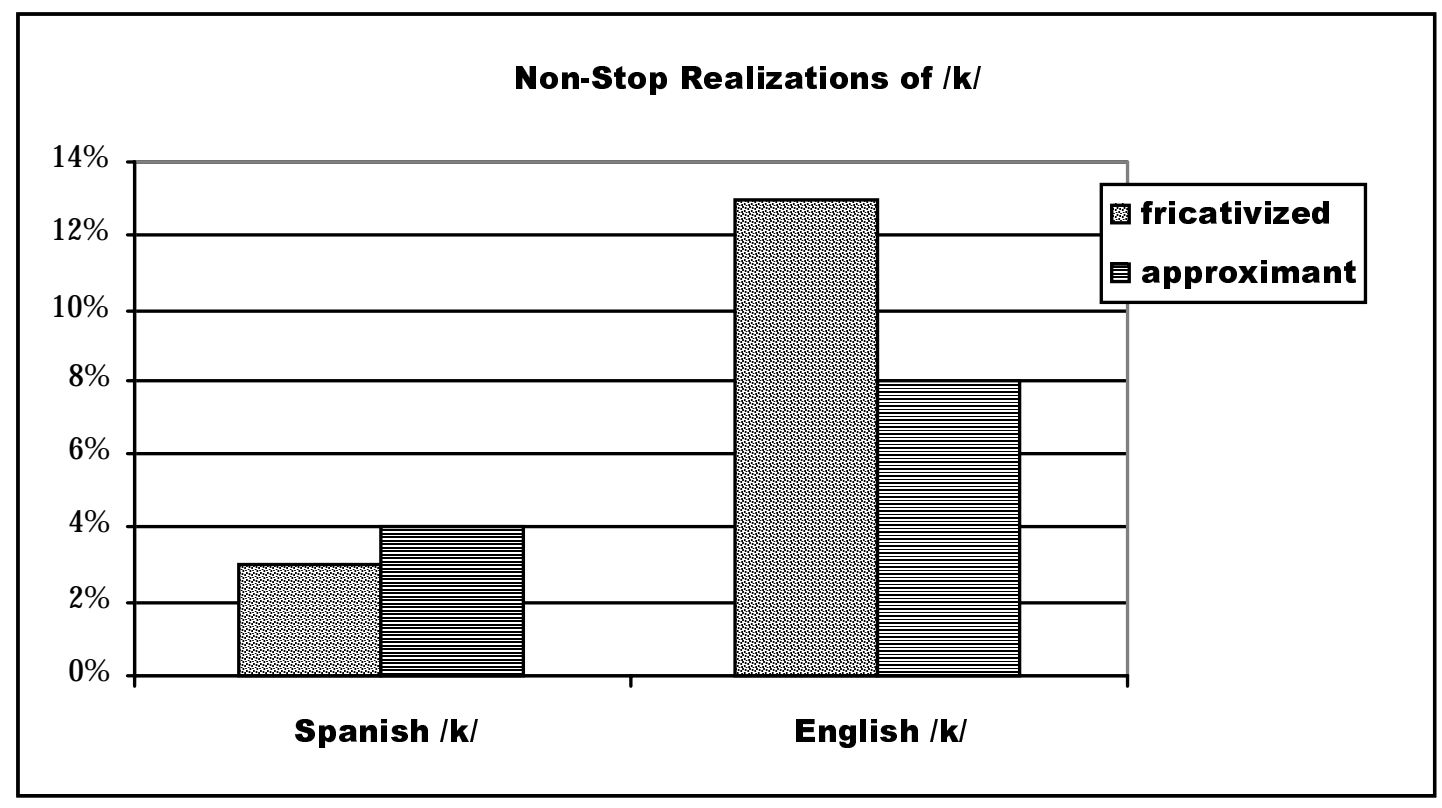

These realizations support the hypothesis that, lacking /x/, English / $\mathrm{k} /$ can be realized with noise, while maintaining the percept of a stop. And the presence of the Spanish $/ \mathrm{x} /$ prevents $/ \mathrm{k} /$ from infringing on $/ \mathrm{x} / \mathrm{s}$ phonetic space.

Before closing the section on manner of articulation of $/ \mathrm{k} /$, slightly more discussion of the incompletely closed or stopless stop segments is in order. Although I use terms like weak fricative, fricative, or fricativized to refer to the stops that show noise leaking through when they should be closed, I do not believe they are true fricatives. The noise usually appears less robust than that for a true fricative. Ken Stevens (p.c., 2001) maintains that the constrictions of true fricatives are optimized to produce sufficiently loud frication, concentrated in the appropriate frequency region. Shockey and Gibbon (1993) examined incompletely closed stops in a corpus of palatometer and airflow data and found that those segments which were not underlyingly fricatives were not realized with as much airflow as those that are truly 
fricatives. Shockey and Gibbon refer to them as stopless stops. More data are needed to compare real fricatives to these reduced variants of $/ \mathrm{k} /$.

\section{$3 \quad$ More predictions about the role of inventory in constraining variation}

Having shown the role of the inventory in constraining variation in English and Spanish /k/, I turn to other accessible cases which may be used to test the role of the inventory. These cases include two more in English, the interdental fricatives, and stop releases, as well as predictions for velars in German and French.

\subsection{Interdental fricatives}

English interdental fricatives are often realized as stops. A common stereotype of Brooklyn, New York speech has the interdental fricatives $/ \theta$, $\partial /$ realized as stops, so that these guys comes out as dese guys. When speaking English, native speakers of languages without interdental fricatives often replace the English interdental fricatives with stops, such that French speakers produce a thin that sounds more like tin. In its inventory of coronal stops, English has only alveolar stops phonemically, but no contrasting dental stops. Since the English inventory includes phonemic interdental fricatives but no phonemic dental stops, speakers should be free to realize these fricatives as dental stops without risk to the phonemic system. Because of the holes in the English dental category, stop or approximant realizations of the interdental fricatives should be possible.

(22) Partial inventory of English dental and alveolar consonants

\begin{tabular}{|c|c|c|}
\hline & dental & alveolar \\
\hline stop & & $\mathrm{t} \quad \mathrm{d}$ \\
\hline fricative & $\theta$ & $\mathrm{s}$ \\
\hline approximant & & r \\
\hline
\end{tabular}

The three examples below all come from the word thorough read in the carrier phrase Please say thorough for me. (23) has $/ \theta /$ as a regular fricative; (24) has an incomplete stop; and (25) has a complete dental stop.

(23) English $/ \theta /$ in thorough as regular fricative

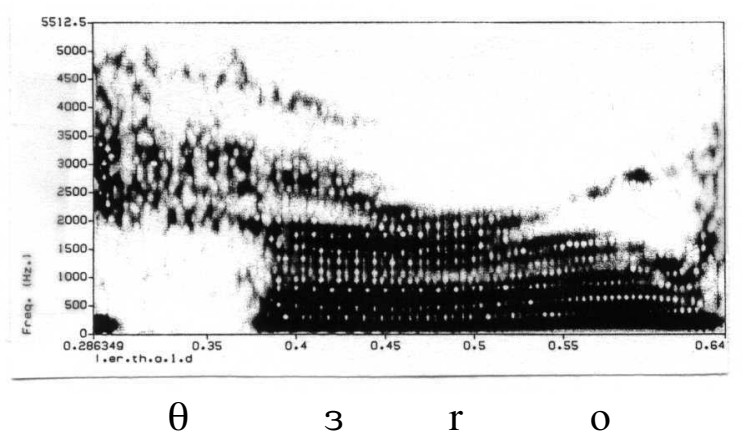


(24) English $/ \theta /$ in thorough with noise and burst

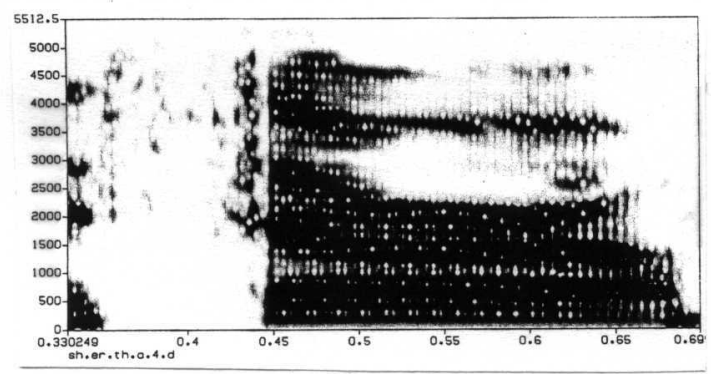

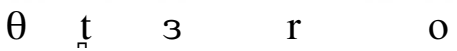

(25) English $/ \theta /$ in thorough as dental stop

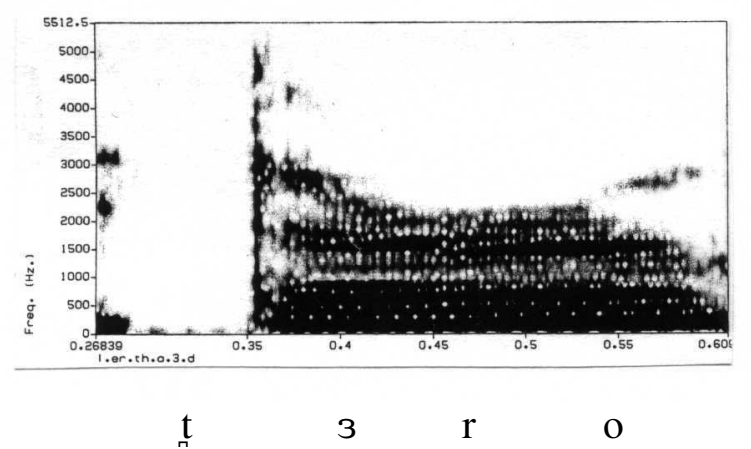

It is true that the interdental fricative can be realized as a stop. In all three cases, the words sound as if they were produced with a voiceless interdental fricative, with the more stop-like realizations falling below notice. Because the words and the environment are the same in all three cases, either the variation is random or the conditioning factors must be sought elsewhere.

\subsection{Stop releases on American National Public Radio (NPR)}

Another example in American English where speakers manipulate non-contrastive elements is on National Public Radio (NPR). The style of many NPR announcers shows very robust releases to utterance-final stops. The releases are so robust that the stops seem to be affricated. Based on the hypothesis presented to this point, affricated stops would be fine because, except for the palatoalveolar affricates, there are no contrastive affricated stops. Mark Tiede (p.c., 2001) suggests that it is precisely in the non-contrastive areas that language tends to "bulge out" and speakers show some creativity.

\subsection{Predictions for German and French velars}

German and French are other possible languages to look at with respect to this hypothesis. The appropriate sections of the phoneme inventories for German and French are given below:

(26) German

\begin{tabular}{|l|c|}
\hline & velar \\
\hline stop & $\mathrm{k}$ \\
\hline fricative & $\mathrm{x}$ \\
\hline
\end{tabular}

(27) French

\begin{tabular}{|l|c|}
\hline & velar \\
\hline stop & $\mathrm{k}$ \\
\hline fricative & IIIIIIIIIIIIIIIIIIII \\
\hline
\end{tabular}


Since German has both a phonemic velar stop and a phonemic velar fricative, the German / $/ \mathrm{k}$ should always be realized as a stop to avoid overlap with the fricative phoneme. Most varieties of French, on the other hand, have no phonemic velar fricative and so $/ \mathrm{k} /$ could vary from a stop. While a prediction based simply on the inventory of French velars is easy, it is also important to remember that French stops typically have very clear release bursts. To achieve such a salient release, the speaker must make a complete closure, so there is an additional factor requiring the French $/ \mathrm{k} /$ to be realized as a full stop. In all cases, it is important to consider the language-specific articulatory tendencies and their possible impact on variation.

This paper has illustrated the wider range of variation that is seen in consonants and shown that the language's phoneme inventory plays a role in constraining that variation. This variation has a number of possible applications.

\section{$4 \quad$ Applications and theoretical implications of consonant variation}

The results of studies of consonant variation can be useful in many areas of applied and theoretical linguistics. In linguistics applied to speech technology, a model of variation could yield improved automatic speech recognition and more natural speech synthesis. In second language acquisition, a better understanding of variation may help learners understand colloquial speech, as well as improve their accents and sound more native. In studies of speech style or rate, consonant variation may be able to serve as a quantitative diagnostic of the style or rate, which would be helpful in some areas of sociolinguistics.

Consonant behavior has good potential as a diagnostic of speech style. Up to now, there have been attempts to develop vowel-based diagnostics of style, focusing on vowel reduction and centralization as hallmarks of an informal style. Vowel-based diagnostics are very time-consuming because of the need to calculate formant frequency baselines for each vowel and subject before calculating differences from those baselines. A consonant-based diagnostic would not require the setting of baselines; rather, the citation form of the consonant could be taken as the baseline and differences from that form could be calculated directly and quickly.

Consonants are important not only for applied research, but also to theoretical questions. Theoretically, consonant behavior can have implications for the representation of segmental variation, the relationship between consonant and vowel elements, the correspondence between places of articulation, and the impact of categorical perception on consonants. At the extreme, the results of studies of variation may cause us to rethink our underlying representations. Certainly, it is important to determine where in the phonetics or phonology the range of possible segment variation resides, if it does reside within the phonetics or phonology. The range of possible or acceptable variation is something that might need to be represented.

Phonologically, the study of reduction in consonants can yield insights into the relationship between the consonant and vowel tiers in some versions of autosegmental phonology, in particular the degree of linkage between the tiers. Does reduction in vowels imply concomitant reduction in consonants and/or vice versa? Studies of reduction of both consonants and vowels will help answer the very important question of whether or not consonants and vowels reduce in tandem and if a measure of reduction can be correctly taken to imply reduction in the other. The question of how detailed phonetic place of articulation fits with categorical phonological place of articulation is also important in consonant variation. For example, this study classes the interdental fricatives as dental to oppose them to 
alveolars. While grouping interdental and dental seems appropriate in this case, there are other groupings that may be more problematic. For example, how do the correspondences between the various other coronal places work? Will the presence of a phonemic palatoalveolar affricate prevent an alveolar stop from affricating? Will the presence of a phonemic labiodental fricative prevent a labial stop from being realized as a labial continuant? Results of studies of consonant variation may yield different natural groupings of places of articulation.

Because consonants are often produced with other than their citation manner of articulation, but listeners are seldom aware of it, categorical perception must be playing a role. Categorical perception of manner of articulation is an area where more detailed perceptual testing is needed. When consonants are produced with other than their expected manner of articulation, what do listeners detect? Do listeners perceive only the intended phoneme or can they judge where the realization fits on a continuum of possible acceptable realizations? Perceptual studies will be important because categorical perception obscures more consonant variation than was previously thought. Determining the range of acceptable realizations for consonants can provide additional data to test the role of phoneme inventory in constraining variation.

\section{$5 \quad$ Conclusions}

Consonants show a great deal of variation from their citation forms in connected speech but that phonetic variation respects the phoneme inventory in some ways. A comparison of English and Spanish /k/ has shown the role of inventory in constraining variation. Spanish /k/ may not receive a more open articulation because that would interfere with the contrasting velar fricative /x/. English / $/ \mathrm{k} /$ is free to receive an open articulation because English has no contrasting velar fricative. Likewise, English interdentals are free to be realized as stops because English has no contrasting dental stops. About $10 \%$ of the variation is accounted for by reference to the inventory. Although that is certainly not all the variation, it is significant when considering that many factors affect segmental realization. Studies of consonant variation contribute both to phonetic and phonological theory, offering potentially rich theoretical rewards.

\section{References}

Anderson, A.H., M. Bader, E.G. Bard, E. Boyle, G. Doherty, S. Garrod, S. Isard, J. Kowtko, J.M. McAllister, J. Miller, C. Sotillo, H. Thompson, R. Weinert. 1993. The HCRC map task corpus. Language and Speech 34, 351366.

Ball, M. and J. Rahilly. 1999. Phonetics: The Science of Speech. London: Arnold Publishing.

Barry, W.J. 1996. Some fundamental problems of looking at connected speech. Arbeitsberichte 31. Institut für Phonetik und Digitale Sprachverarbeitung, Kiel University, 113-118.

Bell, A., D. Jurafsky, E. Fosler-Lussier, C. Girand, and D. Gildea. 1999. Forms of English function words-Effects of disfluencies, turn position, age and sex, and predictability. Proceedings ICPhS 14, 395-398.

Brown, G. 1990. Listening to Spoken English. 2nd ed. London and New York: Longman.

Butcher, A. 1996. Some connected speech phenomena in Australian languages: Universals and idiosyncrasies. Arbeitsberichte 31. Institut für Phonetik und Digitale Sprachverarbeitung, Kiel University, 83-104.

Byrd, D. 2000. Articulatory vowel lengthening and coordination at phrasal junctures. Phonetica 57, 3-16.

Byrd, D. 1994. Relations of sex and dialect to reduction. Speech Communication 15, 39-54.

Byrd, D. A. Kaun, S. Narayanan, and E. Saltzman. 2000. Phrasal signatures in articulation. In M. Broe \& J. Pierrehumbert (eds) Papers in Laboratory Phonology V: Acquisition and the Lexicon, 70-87. Cambridge: Cambridge University Press. 
Byrd, D. and E. Saltzman. 1998. Intragestural dynamics of multiple prosodic boundaries. Journal of Phonetics 26, 173-199.

Crystal, T. and A. House. 1988. The duration of American English stop consonants: an overview. Journal of Phonetics 16, 285-294.

de Jong, K. 1995. The supraglottal articulation of prominence in English. JASA 97, 491-504.

Duez, D. 1995. On spontaneous French speech: Aspects of the reduction and contextual assimilation of voiced stops. Journal of Phonetics 23, 407-427.

Engstrand, O. and F. Lacerda. 1996. Lenition of stop consonants in conversational speech: Evidence from Swedish. Arbeitsberichte 31. Institut für Phonetik und Digitale Sprachverarbeitung, Kiel University, 31-41.

Fougeron, C. 1998. Variation articulatoire en début de constituants prosodiques de différents niveaux en français. Paris III Doctoral Dissertation.

Fougeron, C. and P. Keating. 1997. Articulatory strengthening at edges of prosodic domains, Journal of the Acoustical Society of America 101, 3728-3740.

Fowler, C.A. and J. Housum. 1987. Talkers' signaling of "new" and "old" words in speech and listeners' perception and use of the distinction. Journal of Memory and Language 26, 489-504.

Fox Tree, J.E. and H.H. Clark. 1997. Pronouncing "the" as "thee" to signal problems in speaking. Cognition 62, 151167.

Helgason, P. 1996. Lenition in German and Icelandic. Arbeitsberichte 31. Institut für Phonetik und Digitale Sprachverarbeitung, Kiel University, 219-226.

Jespersen, O. 1904. Lehrbuch der Phonetik. Leipzig and Berlin.

Jongman, A., S. Blumstein and A. Lahiri. 1985. Acoustic properties for dental and alveolar stop consonants: A cross-language study. Journal of Phonetics 13, 235-251.

Jurafsky, D., A. Bell, E. Fosler-Lussier, C. Girand, and W. Raymond. 1998. Reduction of English function words in Switchboard. Proceedings of ICSLP-98, Sydney.

Kohler, K. 1990. Segmental reduction in connected speech in German: Phonological facts and phonetic explanations. In W.J. Hardcastle and A. Marchal (eds). Speech Production and Speech Modeling. 6-92. The Netherlands: Kluwer Academic Publishers.

Language Files. 1999. Columbus, Ohio: The Ohio State University Press. 8th edition.

Lavoie, L. to appear. Some influences on the realization of for and four in American English. Journal of the International Phonetic Association.

Lavoie, L. 2001. Consonant Strength: Phonological Patterns and Phonetic Manifestations. New York: Garland Publications.

Manuel, S. 1990. The role of contrast in limiting vowel-to-vowel coarticulation in different languages. Journal of the Acoustical Society of America 88, 1286-1298.

Ohala, J. 1996. The relation between sound change and connected speech processes. Arbeitsberichte 31. Institut für Phonetik und Digitale Sprachverarbeitung, Kiel University, 201-206.

Pierrehumbert, J. 1994. Knowledge of variation. CLS 30 (Papers from the 30th Regional Meeting of the Chicago Linguistic Society; Volume 2: The Parasession on Variation in Linguistic Theory), 232-256.

Pierrehumbert, J. and D. Talkin. 1992. Lenition of /h/ and glottal stop. In G.R. Docherty and D.R. Ladd (eds) Papers in Laboratory Phonology II: Gesture, Segment, Prosody. 90-127. Cambridge: Cambridge University Press.

Shockey, L. and F. Gibbon. 1993. "Stopless stops" in connected English. Speech Research Laboratory University of Reading Work in Progress, 1-7.

van Son, R. and L. Pols. 1999. An acoustic description of consonant reduction. Speech Communication 28, $125-140$.

Whalen, D., C. Best, and J. Irwin. 1997. Lexical effects in the perception and production of American English /p/ allophones. Journal of Phonetics 25, 501-528.

Zec, D. 1995. Sonority constraints on syllable structure. Phonology 12, 85-129. 